\title{
BMJ Open General practitioners' views and experiences in caring for patients after sepsis: a qualitative interview study
}

\author{
Sabine Gehrke-Beck, ${ }^{1}$ Jochen Gensichen, ${ }^{2,3,4}$ Katrina M Turner (iD , ${ }^{5}$ \\ Christoph Heintze, ${ }^{1}$ Konrad FR Schmidt (D) , ${ }^{1,3,4}$ SMOOTH Study Group
}

To cite: Gehrke-Beck S, Gensichen J, Turner KM, et al. General practitioners' views and experiences in caring for patients after sepsis: a qualitative interview study. BMJ Open 2021;11:e040533. doi:10.1136/ bmjopen-2020-040533

- Prepublication history for this paper is available online. To view these files, please visit the journal online (http://dx.doi. org/10.1136/bmjopen-2020040533).

$\mathrm{CH}$ and KFS contributed equally.

Received 18 May 2020

Revised 23 December 2020

Accepted 07 January 2021

Check for updates

(c) Author(s) (or their employer(s)) 2021. Re-use permitted under CC BY-NC. No commercial re-use. See rights and permissions. Published by BMJ.

${ }^{1}$ Institute of General Practice and Family Medicine, Charite University Medicine Berlin, Berlin, Germany

${ }^{2}$ Institute of General Practice and Family Medicine, University Hospital Munich, Munchen,

Germany

${ }^{3}$ Institute of General Practice and Family Medicine, Jena University Hospital, Jena, Germany ${ }^{4}$ Center of Sepsis Care and Control, Jena University Hospital, Jena, Germany

${ }^{5}$ Population Health Sciences, Bristol Medical School, Bristol, UK

Correspondence to

Dr Konrad FR Schmidt;

Konrad.Schmidt@charite.de

\section{ABSTRACT}

Background Patients surviving critical illnesses, such as sepsis, often suffer from long-term complications. After discharge from hospital, most patients are treated in primary care. Little is known how general practitioners (GPs) perform critical illness aftercare and how it can be improved. Within a randomised controlled trial, an outreach training programme has been developed and applied. Objectives The aim of this study is to describe GPs' views and experiences of caring for postsepsis patients and of participating a specific outreach training.

Design Semistructured qualitative interviews.

Setting 14 primary care practices in the metropolitan area of Berlin, Germany.

Participants 14 GPs who had participated in a structured sepsis aftercare programme in primary care.

Results Themes identified in sepsis aftercare were: continuity of care and good relationship with patients, GP's experiences during their patient's critical illness and impact of persisting symptoms. An outreach education as part of the intervention was considered by the GPs to be acceptable, helpful to improve knowledge of the management of postintensive care complications and useful for sepsis aftercare in daily practice.

Conclusions GPs provide continuity of care to patients surviving sepsis. Better communication at the intensive care unit-GP interface and training in management of long-term complications of sepsis may be helpful to improve sepsis aftercare.

Trial registration number ISRCTN61744782.

\section{INTRODUCTION}

An increasing number of patients are treated in intensive care units (ICUs) and survive a critical illness such as sepsis. ${ }^{1}$ After discharge, patients may suffer from long-term consequences, ${ }^{2}$ such as critical illness polyneuropathy, critical illness myopathy, cognitive decline, chronic pain, ${ }^{3-6}$ depression or posttraumatic stress disorder. ${ }^{3} 8$ These sequelae are referred to as the "postintensive care syndrome' (PICS). ${ }^{1}$ They result in lower health-related quality of life and elevated mortality rates, as well as increased healthcare use. ${ }^{9-11}$

\section{Strengths and limitations of this study}

- This is the first study to explore in detail general practitioners' (GPs) views of managing sepsis survivors.

- Using qualitative interviews meant GPs could raise issues that were salient to them.

- Some of the interviews were short due to GPs having limited time to take part.

Only GPs in one metropolitan area were interviewed.

International guidelines state that patients with PICS should have ongoing, long-term monitoring and therapy. ${ }^{12}{ }^{13}$ Some patients discharged from ICUs are referred to ICU follow-up clinics. The purpose and structure of these clinics vary between countries, but change of clinical outcomes are rarely shown. ${ }^{14-17}$ In addition, continuity of care at an ICU follow-up clinic may be difficult when the patient lives far from the ICU and needs frequent follow-up. ${ }^{18-20}$ Even if intensive care doctors and nurses are familiar with complications after critical illness, their role in coordinating ICU follow-up is discussed controversially ${ }^{1721}$ : They seem not to be trained in outpatient care coordination and the clinical variety of possible post-ICU complications. ${ }^{17}$ Additionally, they do not know their patients for long and therefore may lack insight into the patient's psychosocial background. ${ }^{22}$ On the contrary, general practitioners (GPs) have a long-lasting relationship with their patients and provide care coordination as a core task ${ }^{23}$ which is highly appreciated by the patients. ${ }^{24}$ This makes GPs ideal advocates of patients in their rehabilitation pathways. Thus, a Dutch retrospective cohort study found an increased consultation rate in primary care following ICU discharge. ${ }^{25}$ Considering that there were more than two million intensive care treatment cases just in Germany in $2017^{26}$ and an assumed increase driven by the COVID-19 pandemic, ${ }^{27}$ GPs need to know how to provide best postintensive care to these patients, as it 
has been already called for by others. ${ }^{28}$ The concept of the PICS is quite recent, but GPs' intensive care experiences may date back to medical studies or early hospital rotations. In a qualitative study, GPs reported lack of background knowledge and confidence in diagnosing and treating postsepsis complications. ${ }^{29}$ Kahn and Angus ${ }^{22}$ states that GPs need to be educated in how to care for patients after critical illness but do not provide suggestions about how this should be done. ${ }^{22}$

Outreach education delivered by academics to the GPs appeared to change their clinical behaviour and improve patient care ${ }^{30}$ However, current evidence mainly focuses on changing prescribing patterns rather than on complex treatment strategies. Educational outreach visits providing knowledge to primary care for relatively rare medical problems are shown to enhance confidence ${ }^{31}$ and are acceptable to GPs. ${ }^{32}$ Such an intervention may be effective in educating GPs in how to effectively care for patients with PICS. However, whether it is needs to be assessed.

The SMOOTH trial evaluated a structured aftercare programme in general practice for sepsis survivors including an outreach education for GPs. ${ }^{33}{ }^{34}$ Sepsis is one of the leading causes of long-term-ICU stays and can be viewed as a model illness for critical disease. ${ }^{35}$ The intervention evaluated in the trial was designed with reference to the Chronic Care Model $^{36}$ at the level of a GP practice. It is focused on patient empowerment, a proactive care team and case management to ensure continuity of care. The trial did not find an improvement in mental health-related quality of life at 6 months after ICU discharge compared with usual care. ${ }^{33}$ As part of this trial, in-depth interviews were held with GPs to explore their experiences with patients discharged from ICU and the intervention. Qualitative research has been conducted with post-ICU patients in detail ${ }^{37-43}$ but, to date, no one had explored in depth the views and experiences of GPs caring for these patients. The aim of this study is to describe GPs' views and experiences of caring for postsepsis patients and of participating a specific outreach training, in order to inform and contribute to applicable future aftercare structures in primary care.

\section{METHODS \\ The SM00TH trial}

The SMOOTH trial is a multicentre randomised controlled trial (RCT) evaluating a primary care based aftercare intervention for sepsis survivors. The intervention included monitoring of the patient by a case manager (a specialised nurse), a patient education session delivered by the case manager and an educational outreach visit by a liaison physician to the GP; details are reported elsewhere. ${ }^{33}$ Patients were recruited in the ICU, and when they agreed to participate, their GPs were contacted and asked to join also the trial. Two hundred and ninety-one patients agreed to participate, with 148 patients were randomised to the intervention and 143 patients to the control group receiving usual care. As some patients changed their GPs during the trial, the number of GPs was slightly larger than the number of patients. Three hundred seven GPs were approached to participate. Two hundred and ninety-four $(95.8 \%)$ agreed and were included in the trial. Of the total 159 GPs in the intervention group, 55 were recruited at the Berlin trial site.

The intervention directed at the GP consisted of one outreach educational visit by a liaison physician-a GP trained in sepsis aftercare. The visit was scheduled after the patient's discharge and according to time preferences of the GPs. It took place in the GP practice and lasted about one hour. The education session included a brief overview of sepsis epidemiology and diagnosis, including red flags in primary care, but focused specifically on the six most common sequelae of sepsis ('Sepsis Six'). The epidemiology of long-term sequelae, practical tools for diagnoses and monitoring, as well as evidence-based therapeutic options in routine outpatient care were presented. A detailed manual covering all the information given and a brief sepsis pocket card summarising main points for everyday practice were handed over to the GP, published elsewhere. $^{34}$ The GP was asked to contact the liaison physician later at any moment in the study if questions arose during follow-up of the patient.

\section{Study design and data collection}

As part of implementation evaluation, semistructured interviews were held with the GPs in the intervention group of the RCTs to gain insight into their experiences caring for patients surviving sepsis and the GP education that had been delivered as part of the intervention.

Qualitative methods are applied within the research paradigm of critical realism to complete the results of the quantitative evaluation using a qualitative exploration. ${ }^{44}$ Critical realism can be used to understand the complexities in primary care and events and phenomena in this setting. ${ }^{45}$ The aim was to illuminate and understand the functioning of the intervention in the social background of a GP practice and to extract suggestions for future and optimised aftercare in general practice.

The research team consisted of a fourth year medical student (NS), who conducted the interviews as part of a research project and four academic GPs (SGB, CH, KS and JG) who were involved in analyses of the data. NS had received training in qualitative research interviews and was regularly supervised throughout the study by SGB and $\mathrm{CH}$, who are experienced qualitative researchers. NS had not been involved in the SMOOTH trial, and interviewees were informed of this, to ensure they felt comfortable making any negative comments about the trial. SGB, $\mathrm{CH}, \mathrm{KS}$ and JG were involved in the trial. At the time of the interviews, they were not aware that the outreach education did not change patient's mental health-related quality of life (primary outcome).

A topic guide was developed and based on the aims of the study and an understanding of relevant literature. The questions included focused on the GPs' experiences of caring for patients who had survived sepsis and their experiences of the trial intervention. 
We purposefully sampled GPs for interview to ensure interviews were held with GPs of varying gender and duration of work experience. All those approached for interview had worked at the Berlin trial site. If GPs were willing to be interviewed, they were mailed information about the interviews and a consent form. GPs willing to be interviewed could stipulate the time and location of their interview. The first interview was used as a pilot, but as no changes were made to the topic guide, this interview was included in the analysis. With participant consent, the interviews were audiotaped and transcribed verbatim by NS. GPs were interviewed until data saturation was reached; that is, when no new themes were identified in the later interviews.

\section{Patient and public involvement}

Patient's perspectives and needs were included into topic guide development by the study team. Beside literature research, it was based on the results of qualitative interviews with sepsis survivors, using the same methodical approach and being published elsewhere. ${ }^{42}$

\section{Data analysis}

The interviews were analysed thematically. ${ }^{46}$ Inductive thematic coding was used to gain an overall insight into the perspectives of the GPs. Transcripts of four interviews were read and reread by different members of the research team (SGB, CH, KS and JG) who identified themes and developed initial coding frames. These researchers repeatedly discussed their codes and interpretation of the data. Once the coding frames had been agreed, they were applied to all interviews (see table 1A and B). Coding was done manually by SGB. Results were presented to the research team and discussed until consensus was reached (SGB, CH, JG and KS).

\section{RESULTS \\ Participants}

We contacted 18 GPs for interview. Four GPs declined to participate due to lack of time. The 14 GPs who agreed to be interviewed (table 2) chose to be interviewed at work, on practice premises, in a private room. Details of the patients the GPs cared for are shown in table 3. After 14 interviews, theoretical saturation was reached with no new aspects emerging in the last two interviews. The interviews were conducted from January to August 2013 and lasted 12-28 min (mean $20 \mathrm{~min}$ ). Themes considered relevant to this paper with corresponding quotes are shown in tables 4 and 5 .

\section{Caring for patients after critical illness}

When analysing the GPs' accounts, three main themes related to their experience of caring for patients after intensive care were identified as continuity of care and good relationship with patients, GP's experiences during their patient's critical illness and impact of persisting symptoms after discharge.
Table 1 (A) Coding framework: caring for patients after critical illness. (B) Coding framework: impact of the outreach education

\begin{tabular}{|c|c|}
\hline Themes & Subthemes \\
\hline \multicolumn{2}{|c|}{$\begin{array}{l}\text { (A) Coding framework: caring for patients after critical } \\
\text { illness }\end{array}$} \\
\hline $\begin{array}{l}\text { Continuity of } \\
\text { care and good } \\
\text { relationship with } \\
\text { patients }\end{array}$ & $\begin{array}{l}\text { Previous health status } \\
\text { Personality and illness behaviour } \\
\text { Social background } \\
\text { Continuity of care }\end{array}$ \\
\hline $\begin{array}{l}\text { GP's experiences } \\
\text { during their patient's } \\
\text { critical illness }\end{array}$ & $\begin{array}{l}\text { Lack of information } \\
\text { Emotional impact }\end{array}$ \\
\hline \multirow[t]{4}{*}{$\begin{array}{l}\text { Impact of persisting } \\
\text { symptoms }\end{array}$} & $\begin{array}{l}\text { General weakness and limited } \\
\text { functioning }\end{array}$ \\
\hline & Alteration to presepsis condition \\
\hline & $\begin{array}{l}\text { Specific diagnosis of common } \\
\text { complications after intensive care }\end{array}$ \\
\hline & Individual complication \\
\hline \multicolumn{2}{|c|}{ (B) Coding framework: impact of the outreach education } \\
\hline \multirow[t]{2}{*}{ Acceptability } & Convenience by outreach visit \\
\hline & Time strains and competing tasks \\
\hline \multirow[t]{4}{*}{$\begin{array}{l}\text { Improvement of } \\
\text { knowledge }\end{array}$} & $\begin{array}{l}\text { Persisting elevated mortality after } \\
\text { discharge }\end{array}$ \\
\hline & $\begin{array}{l}\text { Specific long-term complications } \\
\text { (polyneuropathy and post-traumatic } \\
\text { distress) }\end{array}$ \\
\hline & Diagnosis of sepsis \\
\hline & Relevant summary for practice \\
\hline \multirow[t]{4}{*}{ Transfer into practice } & Identifying complications \\
\hline & Initiation of specific therapy \\
\hline & Diagnosis of sepsis \\
\hline & $\begin{array}{l}\text { Low relevance as small patient } \\
\text { numbers in practice }\end{array}$ \\
\hline
\end{tabular}

This study refers to the standards for reporting qualitative research. ${ }^{56}$

GPs, general practitioners.

\section{Continuity of care and good relationship with patients}

At the start of the interview, the GPs were asked to talk freely about their patient. The accounts given suggested that specific medical diagnoses and the acute sepsis diagnosis played a limited role in the GPs' narration. GPs often commented on the patient's condition before they were diagnosed with sepsis, discussing their pre-existing disease and previous general health status. It was evident that many of them were familiar with the patients' medical history.

Many GPs also talked about the patient's personality. They often focused on the patient's coping and illness behaviour as one GP explained:

... she is actually a very modest... and shy person and for her medical problems she only claimed what she 
Table 2 Self-declared details of interviewed general practitioners (GPs). $(\mathrm{N}=14)$

\begin{tabular}{lc}
\hline Age* (years) $^{*}$ & $41-68$ (mean: 55$)$ \\
Sex & N (\%) \\
\hline Male & $8(42.9)$ \\
Female & $6(57.2)$ \\
\hline
\end{tabular}

\section{Practice organisation}

$\begin{array}{ll}\text { Joint practices (2-6 GPs) } & 6(57.2) \\ \text { Single practices } & 8(42.9)\end{array}$

\begin{tabular}{|c|c|}
\hline \multicolumn{2}{|l|}{ Licence to practice since* } \\
\hline 10-20years & $1(7.1)$ \\
\hline 20-30years & $3(21.4)$ \\
\hline $30-40$ years & $6(57.2)$ \\
\hline$>40$ years & $2(14.3)$ \\
\hline No data & $2(14.3)$ \\
\hline \multicolumn{2}{|l|}{ Practice opening* } \\
\hline$<10$ years & $1(7.1)$ \\
\hline 10-20years & $5(35.7)$ \\
\hline 20-30years & $4(28.6)$ \\
\hline $30-40$ years & $4(28.6)$ \\
\hline \multicolumn{2}{|l|}{ Specialisation } \\
\hline GPs & $7(50)$ \\
\hline General internists $\dagger$ & $6(57.2)$ \\
\hline Practitioner without specialisation & $1(7.1)$ \\
\hline \multicolumn{2}{|c|}{ Practice characteristics, subspecialisations $\ddagger$ ) } \\
\hline Complementary medicine & $7(50)$ \\
\hline Psychosomatics & $3(21.4)$ \\
\hline Pain management & $2(14.3)$ \\
\hline Gastroenterology & $1(7.1)$ \\
\hline Infectiology & $1(7.1)$ \\
\hline Oncology & $1(7.1)$ \\
\hline Diabetology & $1(7.1)$ \\
\hline
\end{tabular}

\section{Home visits per week}

\begin{tabular}{|c|c|}
\hline$<5$ & $3(21.4)$ \\
\hline $5-10$ & $4(28.6)$ \\
\hline$>10$ & $2(14.3)$ \\
\hline None & $2(14.3)$ \\
\hline No data & $3(21.4)$ \\
\hline \multicolumn{2}{|c|}{ Patients > 60 years (estimate) } \\
\hline$<30 \%$ & $5(35.7)$ \\
\hline $30 \%-50 \%$ & $6(57.2)$ \\
\hline$>50 \%$ & $2(14.3)$ \\
\hline \multicolumn{2}{|c|}{ Academic teaching practice } \\
\hline Yes & $7(50)$ \\
\hline No & $7(50)$ \\
\hline
\end{tabular}

${ }^{*}$ At the time of the interview.

†A considerable proportion of primary care in Germany is provided by general internists.

$\ddagger$ Multiple mention possible.
Table 3 Characteristics of postsepsis patients cared for by the general practitioners $(\mathrm{N}=14)$

\begin{tabular}{ll}
\hline Age (years) & $45-82$ (mean 66) \\
\hline Sex & $\mathbf{N}(\%)$ \\
\hline Male & $11(78.6)$ \\
\hline Female & $3(21.4)$ \\
Sepsis focus & $\mathbf{N}(\%)$ \\
\hline Pulmonal & $3(21.4)$ \\
Gastrointestinal & $2(14.3)$ \\
Renal & $3(21.4)$ \\
Tissue infection & $3(21.4)$ \\
Unknown & $3(21.4)$ \\
\hline
\end{tabular}

really needed urgently at that moment. A very kind and pleasant patient. GP 12

Some GPs also reported on the personal and employment situation of their patients, especially if they felt that this had been important to the recovery of the patient:

Despite being my age, she had a young daughter and I think that's why she needed to be functioning and go back to work and she needed the money, yes. GP 6

Even if most GPs seemed to know their patients very well, two GPs stated that they started caring for their patients only after the sepsis hospital stay:

Well, I basically got to know Mr. (...) only as an acute patient after the hospital admission. He looked for a new GP after this adverse fate happened to him.

These two GPs gave little information about their patients.

GP's experiences during their patient's critical illness

Most GPs commented that they lacked information about the acute sepsis event. They had not been informed about their patient's condition or involved in any of the treatment decisions made while their patient was in hospital. Several GPs could not specify the exact diagnosis and focus of the sepsis.

The event of sepsis itself, as I said, wasn't diagnosed by me, in the practice, but happened in hospital after the operation and that's why I sort of got him back here as everything was finished. I just had to sort of accept that (...) in the end, I didn't have much to do with it and that's why I don't know much about it. GP 8

Some GPs perceived the acute sepsis event as a tragic lifetime event for their patients and discussed the emotional impact of the serious impact on the patient and his or her family.

This was a very unlucky course of events (...) surely, everybody asks, why is it just me? GP 3 
Table 4 Quotations: caring for patients after critical illness

\section{Themes and}

subthemes

\section{Quotation}

\section{Continuity of care and good relationship with patients}

Previous health 'Well, he was a spry patient, he bore his age well and he had no relevant preexisting disease (...) and he came mainly status for check-ups'. GP 9

'Yes, she needed home visits before. She had an insulin-dependent diabetes, COPD, an heavy nicotine abuse she gave up after a hospital admission, we had home oxygen therapy before, there was a problem with alcohol meanwhile, she had skin problems, heart failure, high blood pressure, all that existed before'. GP 5

'A young man, I know him since his school times, over time he developed arterial hypertension. It is obviously in the family, as both his parents suffered from it and a chronic gastritis, apart from this no abnormalities'. GP 3

'I didn't have much contact to (him) before, because he was comparatively fit for his age. He predominantly had orthopedic problems. He is still active, playing golf and so on and (...) but internal diseases, that were serious, he didn't have that'. GP 8

Personality and illness 'She was actually- or she is actually a very modest.... and shy person and for her medical problems she only claimed behaviour what she really needed urgently at that moment. A very kind and pleasant patient'. GP 12

'... (she is a) tall and robust woman, with a croaky voice... a heavy smoker, always unhappy. Niggling, unsatisfied and complaining, but also a fighter'. GP 6

'but she always was...she was a though woman and she never liked taking pills and she eventually said, it is too much, she can't take it and she got used to the symptoms and she would like to take smaller doses (...), she preferred to be without pills'. GP 5

'... well, a rather moaning patient, that came with all kinds of ailments and I considered him generally to be healthier than he himself did'. GP 7

Social background 'She had a quite young daughter. Despite being my age, she had a young daughter and I think that's why she needed to be functioning and go back to work and she needed the money, yes'. GP 6

'.. he himself less, but his wife is quite depressive and that means eventually one has problems in everyday life'. GP 8

'I know the whole family (...) I know him only since about ten years but the rest of the family more than 30 years (...). They are all very scientific, that's what I would say. His wife is in a high position in the administration of veterinary surgeons (...), the son is biologist and works in science and the other daughter is a psychologist'. GP 10

'... she had a comparatively young daughter, despite being my age, she has a young daughter and I think that's why she was in need to come back to normal and go working and she needed the money'. GP 6

Continuity of care 'Well, I basically got to know Mr. (...) only as an acute patient after the hospital admission. He looked for a new GP after this adverse fate happened to him'. GP 2

\section{GP's experiences during their patient's critical illness}

Lack of information 'The event of sepsis itself, as I said, wasn't diagnosed by me, in the practice, but happened in hospital after the operation and that's why I sort of got him back here as everything was finished. I just had to sort of accept that (...) in the end, I didn't have much to do with it and that's why I don't know much about it'. GP 8

'I only saw him again after rehabilitation, I didn't get a discharge letter either. I only got notice of these things as he stood here in front of me'. GP 4

Emotional impact 'This was a very unlucky course of events (....) surely, everybody asks, "why is it just me?"' GP 3

'I once visited him in hospital and was shocked (...) well, this was a dramatic story'. GP 10

\section{Impact of persisting symptoms} and low functioning
General weakness

'Well, she was a shadow of her former self'. GP 6

' $\ldots$ he is not up and about again. Well, he can't leave the flat, he walks short distances like to the toilet, from bed to toilet, from bed to living room'. GP 11

'I have visited him once in the hospital and was shocked. He could only talk slowly, maybe in an orderly way, but he was heavily impaired after this intensive care therapy. And afterwards, it got better, he became clearer from the cerebral point of view and the slowing, that was extreme, went away'. GP 10

'.. in the beginning, she needed house visits, well, I can only see that her health condition only improved very slowly over a long period of time. That's all I can say about it'. GP 12

\footnotetext{
Alteration to presepsis condition

'... but, I must say, (he) had some problems with his peripheral nerves before due to his lifestyle, (due to) alcohol (...) There was some damage before and then, with the sepsis, that only came to the point it became clinically apparent and now that is the situation'. GP 2

'... just like before, she has from time to time exacerbations of her COPD'. GP 12

'... he had depression before and had depression afterwards and I believe his depression was even less, (...) He had a longstanding depression so you can't put these things (sepsis) forward'. GP 10

'... basically, he kept all the diseases he had before and everything grew gradually worse'. GP 11
} 
Table 4 Continued

\begin{tabular}{|c|c|}
\hline $\begin{array}{l}\text { Themes and } \\
\text { subthemes }\end{array}$ & Quotation \\
\hline \multirow{2}{*}{$\begin{array}{l}\text { Specific diagnosis } \\
\text { of common } \\
\text { complications after } \\
\text { intensive care }\end{array}$} & $\begin{array}{l}\text { '... he had this critical illness neuropathy with pains and muscle weakness and at the beginning also psychological } \\
\text { problems with insomnia'. GP } 1\end{array}$ \\
\hline & ' $\ldots$ well, he still has a post traumatic distress syndrome, he is still looking for a psychologist'. GP 4 \\
\hline $\begin{array}{l}\text { Individual } \\
\text { complication }\end{array}$ & ' $\ldots$ and then she was depressive because she had the colostomy'. GP 6 \\
\hline
\end{tabular}

GP, general practitioner.

\section{Impact of persisting symptoms}

GPs mentioned a number of different aspects when they described the condition of their patients after discharge and the impact of sepsis sequelae in their quality of life: general weakness and low functioning, the impact of preexisting diseases, individual specific health impairments and-less frequently-specific diagnosis of longterm complications contributing to PICS.

Many interviewees described a general weakness and low functioning of their patients. They attributed this to the severe illness and the long hospital stay, without specifying the factors and causes contributing to the weakness like underlying illnesses, specific complications or treatment side effects. The focus of their reports was on the consequences for independence and autonomy of their patients rather than underlying pathomechanisms.

\section{Well, she was a shadow of her former self. GP 6}

Many GPs compared their patients' health status to their condition before critical illness. In some cases, they saw their patients' impairment after discharge as, at least in part, attributable to pre-existing and chronic illness. In their perception, the acute sepsis event did not alter status of these patients much.

Essentially, he kept the diseases he had before and everything got gradually a bit worse. He tended to be depressive before and now it isn't much worse. GP 11

The report about their patient condition and complications after sepsis was in many cases given in common, everyday language without listing specific medical diagnoses or specific sepsis complication. They rather concentrated on reporting on everyday functioning and overall well-being. Only some GPs classified specific sepsis sequelae and precisely stated these diagnoses. Some added being only aware of the diagnosis after the education session, they received as part of the study intervention.

And mainly... he was quite distressed by the gait disturbance; by the painful paresthesia he had (...) the polyneuropathy was what was left from the sepsis syndrome. GP 8

Some GPs reported individual complications of sepsis or sepsis therapy had the main impact on the patient's quality of life afterwards, for example, the loss of a limb or a persisting colostomy.

As she had, because of this sepsis, she basically lost the leg, well, she had an amputation and ... hmm... she was still quite mobile before and could leave the flat. Hmm, afterwards no longer, because with one leg she couldn't manage the stairs. GP 5

One GP could not contribute to that aspect, as his patient died shortly after discharge.

\section{Impact of the outreach education}

Three main themes that described the impact of the education session were identified: acceptability, improvement of knowledge and the transfer to professional practice.

\section{Acceptability}

Most participants stated that they appreciated the time and the effort on the side of the liaison physician to come to their premises and adapt to their schedule. They commented that this was an advantage for their own time schedule and comfort.

I was approached at a time that was convenient for me (...), I didn't need to move anywhere, that could happen here, well, the colleague bothered to come (...) and as I said that was ideal, I would say. GP 2

However, some GPs said they had many patients to care for and tasks to cope with and could not spare any time for the training. A few also mentioned that post sepsis patients are rare in a GP practice and that they would rather save time in continuing education for more common diseases.

Well, it was very interesting, the education, but this is just another additional point, that takes time and 
Table 5 Themes, subthemes and quotations: impact of outreach education

\section{Themes and subthemes \\ Quotation}

\section{Acceptability}

Convenience by outreach visit

'I was approached at a time, I had time and as we arranged it, that was ideal (...) it was announced early enough and I got a mail-reminder an I didn't have to move anywhere, that could happen here, well, the colleague was really committed (...) I would say that was ideal'. GP 2

'.... well, that (the outreach education) happened here in the practice ....nice and friendly... adapted to the needs of the doctor... very good, that was comfortable. Didn't burden me much either'. GP 6

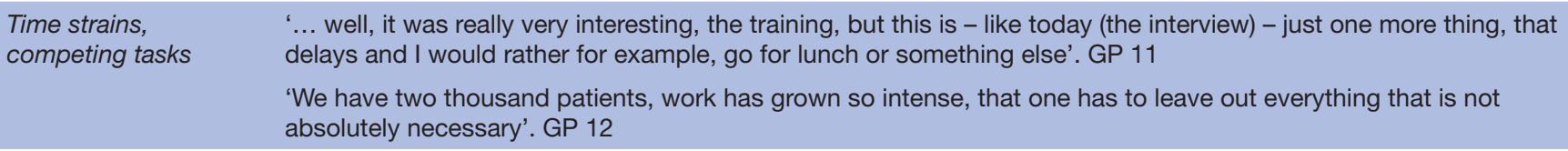

\section{Impact on knowledge}

Persisting elevated mortality after discharge

'The mortality after discharge, (...) that was very impressive, well, because I thought: sepsis overcome, well, everything is fine and the bird flies on'. GP 2

'... that statistic, that said, ok, patients that survived this have a much higher mortality (...) these numbers were quite alarming'. GP 5

Specific long-term complications

'...well, that was mainly new, that one looks at sepsis as a complex illness with long-term complications. I did look at is more as a complication, that, when cured, is presumably good and done with'. GP 11

(polyneuropathy and post-traumatic distress

' $\ldots$ the most helpful was, as I said, the connection. Generally with sepsis, that sepsis can cause other diseases (...) it seems, sepsis can cause serious alterations in the peripheral nerves'. GP 2

'.. the fact, that polyneuropathy had a connection to sepsis was not known to me at all'. GP 12

Diagnosis of sepsis ' '... what kind of symptoms, how sepsis manifests itself, because, one doesn't consider it so much, isn't it?' GP 6

Relevant summary for ' '... we all have learnt that during medical studies, but it is not...one doesn't meet a sepsis survivor every day. It is not practice everyday business. And that's why I found it interesting, that you had it explained again'. GP 5

'.. in continuing education, we don't get the things that are relevant for practice enough, in that way, it was a nice, short update and training, but nothing really new'. GP 8

Transfer to practice

Identifying $\quad$ ' $\ldots$ and since then, I turn my attention more to those symptoms, (...) I really pay attention to things now, that I didn't complications consider before. It really helped me'. GP 6

'One is sensitized for it. Yes, I now pay more attention, especially regarding polyneuropathy and so on, I watch more closely, I say, ok, be careful, here you must consider that, that is a case you must watch out and ask, if she doesn't tell herself, whether she has symptoms'. GP 5

$\begin{array}{ll}\begin{array}{l}\text { Initiation of specific } \\ \text { therapy }\end{array} & \begin{array}{l}\text { '... now, I would always look first, that I talk with him about what he went through and how it felt in the hospital, what } \\ \text { impressions, what experiences, what feelings and that one really goes on to arrange for psychological care more } \\ \text { quickly'. GP } 4\end{array} \\ \text { '... and I also did some of that in practice, I mentioned the referral to a psychologist and that became very clear'. GP } 4 \\ \text { '... from that training I learnt, that it makes sense, to send the patient to physiotherapy. That it is not only about } \\ \text { medication, his usual medication and putting it - may be a bit trivial- I would prescribe antidepressants as well'. GP } 7\end{array}$

Low relevance as small 'I don't have any patients after sepsis, that's why I can't change what I am doing'. GP 3 patient numbers in practice

I would prefer for example, to have lunch or something similar. GP 11

\section{Improvement of knowledge}

The majority of practitioners stated that they had gained new knowledge from the education. Many interviewees reported it was new to them that sepsis can cause specific disease sequelae into after hospital discharge.

Yes, that was largely new to me, that sepsis is seen as a complex illness with long lasting complications. Till now, I saw it more as a complication, that, when cured, is resolved. GP 11
GPs often also stated that they were not aware that mortality is still elevated long-term after discharge until they heard about that in the education session.

Most helpful was (...) that sepsis for example, has a high mortality, the numbers were alarming! I mean, the mortality after discharge, (...) basically, I thought: Sepsis survived, ok, the bird flies on. GP 2

Some of the GPs reported that they did not know before that polyneuropathy and psychological problems were common consequences after sepsis and intensive care. 
I think, I would not have seen the connection before. Because she had so many other reasons for a polyneuropathy, I would have probably linked it to the diabetes. GP 5

One GP acquired more information about diagnosis of a sepsis in a patient, even though that was not in the focus of the education session.

Some GPs stated that they already knew the information given to them, but even when this was the case, they still appreciated the repetition and summary preparing them for the care of the patient.

Well, I didn't find anything really new to me. But it was brought back and I did concentrate on it and looked closer to it. That was new to me and helps me for, well, aftercare. GP 9

One doctor saw no benefit from the education; he had done research in this field before his GP work and had the relevant knowledge before.

\section{Transfer to practice}

Most of the GPs interviewed said that the new information helped them care for the patient included in the trial and that it would help them in their future work with similar patients. Most of them saw a benefit in identifying sepsis sequelae.

... mainly the polyneuropathy and so on, I look out for it more closely. I say to myself: Look out! You must keep that in mind and ask for it, when they don't tell on their own, if they have problems. GP 5

Some reported consequences for the therapy of the patient they cared for within the study and some stated that they would probably change their therapeutic approach to similar patients in the future.

I believe I changed some things afterwards. I mentioned the psychotherapist afterwards, that became quite clear, and (patient's name) did agree to that. GP 4

One GP had quickly diagnosed a patient with acute sepsis since the training, even though diagnosis of sepsis was not its main focus.

Some GPs doubted the relevance of the information for their work. They stated that caring for similar patients was a very rare event in their practice, and therefore, they did not think they would apply the knowledge they had learnt.

I don't have any sepsis patients - that's why I can't change anything about what I do. GP 3

\section{DISCUSSION}

Findings from this study suggest that GPs provide continuity of care and a good relationship with patients and consider pre-existing and chronic disease, personality and coping patterns, as well as social background, when providing post-ICU care to patients. Many interviewees described the long-term impact of sepsis on their patients as a general weakness and malfunctioning and considered it in relation to the patient's presepsis constitution. Some GPs expressed empathy with the serious life event their patient experienced. GPs reported a lack of information about the course of the disease and their patient's condition while they were in the hospital. Diagnosing and listing specific sepsis sequelae played a minor role.

The outreach education session was acceptable to most GPs. Most GPs acquired new information about long-term complications of sepsis. They considered this information as helpful to identify and start treatment for specific postsepsis symptoms. This finding is consistent with findings from a recent qualitative study critical care nurses delivering a recovery programme to ICU survivors. ${ }^{47}$ However, some GPs did not value it and pointed to the small numbers of postsepsis patients being in competition with other patients and tasks.

While most of the GPs' accounts suggested a longstanding knowledge of the patient and an individual appraisal of their health impairments after discharge, they lacked detailed medical knowledge about sepsis complications. The outreach education was mainly well accepted and seemed to provide a valid setting to improve knowledge about specific diagnostic and therapeutic concepts GPs can apply in their professional practice.

\section{Comparison with existing literature}

Patients' perceptions of their quality of life after an ICU stay have been examined in several qualitative studies. ${ }^{43} \mathrm{~A}$ wide range of ongoing health impairments was identified, and loss of autonomy was a main aspect. ${ }^{37-39}$ The views of the GPs identified here is very close to patients' perspectives. The GPs also reported general weakness and low functioning as a main aspect and a very individual apprehension of complaints and impairment. This congruence may facilitate a patient-centred aftercare especially in a primary care setting.

Difficulties in information flow between ICUs and GPs had been identified before: lack of information about admission or discharge and ongoing needs of patients after an ICU stay and no involvement in treatment decisions were reported by GPs in other studies. ${ }^{48-50}$ As valid data on the course of disease and current diagnoses and treatment is essential for follow-up, information during hospital stay and more detailed discharge information for GPs may be essential to enhance quality in aftercare.

It has been shown that GPs lack information on sepsis and identification of post-ICU complications. ${ }^{29} 50$ The acquisition of clinical knowledge has been described and explained by forming of 'scripts' with repeated exposure to clinical patterns. ${ }^{51}$ With no ongoing experience in handling ICU patients and limited encounters of post-ICU patients, scripts related to the PICS cannot be expected to evolve in GPs in everyday practice. In our study, the educational intervention led to additional knowledge about specific post-ICU complications. This may meet patient's ongoing need for feedback of their ICU history, as well as the resulting impairments. ${ }^{43}$

GPs appreciate personal discussion with experts as a valuable method of continuing education, ${ }^{52}$ and outreach visits as 
a method to reach GPs have been used before and shown to be accepted well. ${ }^{30}$ Knowledge gain has been demonstrated, but transfer to practice seemed to be difficult. ${ }^{30} 53$ Patientrelated intervention may be especially helpful ${ }^{30}$ to facilitate knowledge transfer. In our study, GPs reported transfer to practice of the knowledge they acquired, which may be achieved by the patient-related education and the individual discussion of diagnosis and treatment in the practice.

Lack of continuum of care is a major patient concern after ICU discharge. ${ }^{37} 38$ The Chronic Care Model can be used to inform the ongoing care at the level of an individual practice and also to organise patient-centred trans-sectoral and interdisciplinary care. ${ }^{36}$ Local organisation of a follow-up multiprofessional network and a stepped-care approach could help to ensure continuity of care. This study demonstrates that GPs are familiar with their patients, know about their medical and psychosocial background and consider these aspects when caring for their patients. Therefore, GPs seem to be appropriate ICU aftercare providers. In addition, increased intersectoral information flow could contribute to ensure continuity of care; for example, quality of discharge letters may be improved by training, checklists, software solutions or positive peer pressure. ${ }^{5455}$

\section{Limitations}

Since 307 GPs were asked to take part in the trial, and 294 agreed, it is likely those who took part in the trial are representative of other GPs in Germany. ${ }^{34}$ Being involved in a sepsis aftercare trial informed GPs about the functioning of the RCTs intervention but may have changed their perception of the postsepsis patients they care for. They may have been more preoccupied with and focused on that patient than otherwise. It might be those who agreed to be interviewed were more interested than their peers in sepsis as 4 of the 18 GPs approached for interview declined. As only GPs in the urban area of Berlin were interviewed, specific aspects of GPs in rural settings may have been missed.

The interviews were fairly short, which may limit depth of insights. Time constraints are typical of GPs work and were mentioned repeatedly throughout the interview. As GPs are used to work under pressure, they were able to answer questions quickly and to summarise their experiences. Due to the time pressures they were under, those interviewed were not contacted again to explore whether they agreed with the researchers' analysis of the data. However, themes and subthemes were discussed repeatedly in the research group.

\section{CONCLUSION}

GPs are in a good position to offer continuity of care to sepsis survivors. However, they need training and information flow from secondary care for optimal aftercare provision.

GPs provide a profound and holistic knowledge of these complex patients and to address individually their impairments and residual symptoms. However, lack of specific knowledge about critical illness complications and lack of information and communication with ICU care providers are barriers to optimal follow-up in primary care settings.
GPs should get the necessary background knowledge and individual information of their patients to provide highquality aftercare. Taking into account time constraints and preferred education formats, outreach visits in the context of discharge of a post-ICU patient may be a valuable source of information and support.

Correction notice The following correction made to the published version Christoph Heintze and Konrad FR Schmidt both authors contributed equally.

Acknowledgements Thanks to Nina Schilling (NS) for conducting the interviews and all the GPs interviewed for sharing their time and experiences as well as to Michelle Beuthling and Miriam Hesse for technical support.

Collaborators SM00TH Study Group: Baenfer M, Baldwin LM, Berhold C, Beuthling M, Böde M, Bindara-Klippel A, Brunkhorst FM, Corea M, Davydov D, Eckholdt L, Eissler F, Engel Ch, Fleischmann-Struzek C, Freytag A, Geist A, Gerlach H, Goldmann A, Graf J, Hamzei F, Hartmann M, Hesse M, Huelle K, Jakobi U, Kerth S, Keh D, Klefisch F, Kuehnemund R, Kuhnsch H, Lehmann Th, Lehmke J, Lehmkuhl P, MeierHellmann A, Muehlberg J, Mueller F, Oehmichen F, Ollenschlaeger G, Oppert M, Pohl M, Puthucheary Z, Rademacher S, Reil L, Reinhart K, Sablotzki A, Schelle M, Schelling G, Scherag A, Schilling N, Schneider N, Schreiber T, Schwarzkopf D, Spies C, Thiel P, Tiedemann G, Toepfer L, Toussaint S, Wensing M, Worrack S and von Korff M.

Contributors SGB, KS and $\mathrm{CH}$ had full access to all of the data in the study and take responsibility for the integrity of the data and the accuracy of the data analysis. Study concept and design: SGB, CH, JG and KS. Outreach training conduction: KS. Acquisition and analysis of data: SGB. Interpretation of data: all authors. Drafting of the manuscript: SGB, KS and KMT. Critical revision of the manuscript for important intellectual content: all authors.

Funding This work was supported by the German Center for Sepsis Control \& Care, funded by the German Ministry of Education and Research (grant 01 E0 1002).

Competing interests None declared.

Patient and public involvement Patients and/or the public were involved in the design, or conduct, or reporting, or dissemination plans of this research. Refer to the Methods section for further details.

Patient consent for publication Not required.

Ethics approval The protocol of the SMOOTH trial was approved by the institutional review board of the University of Jena, 26th January 2011 (No.3001/111). The protocol of this interview study was approved by the Ethics Committee of the Charité University Medicine Berlin in April 2013 (No.EA4/023/13).

Provenance and peer review Not commissioned; externally peer reviewed.

Data availability statement Audio recordings and transcriptions of the analysed interviews are stored at a secure server of Charité University Medicine and can be shared on reasonable request.

Open access This is an open access article distributed in accordance with the Creative Commons Attribution Non Commercial (CC BY-NC 4.0) license, which permits others to distribute, remix, adapt, build upon this work non-commercially, and license their derivative works on different terms, provided the original work is properly cited, appropriate credit is given, any changes made indicated, and the use is non-commercial. See: http://creativecommons.org/licenses/by-nc/4.0/.

\section{ORCID iDs}

Katrina M Turner http://orcid.org/0000-0002-6375-2918

Konrad FR Schmidt http://orcid.org/0000-0001-5879-0664

\section{REFERENCES}

1 Needham DM, Davidson J, Cohen $\mathrm{H}$, et al. Improving long-term outcomes after discharge from intensive care unit: report from a stakeholders' conference. Crit Care Med 2012;40:502-9.

2 Desai SV, Law TJ, Needham DM. Long-term complications of critical care. Crit Care Med 2011;39:371-9.

3 Jackson JC, Mitchell N, Hopkins RO. Cognitive functioning, mental health, and quality of life in ICU survivors: an overview. Crit Care Clin 2009;25:615-28. 
4 Ehlenbach WJ, Hough CL, Crane PK, et al. Association between acute care and critical illness hospitalization and cognitive function in older adults. JAMA 2010;303:763-70.

5 Hermans G, De Jonghe B, Bruyninckx F. Clinical review: critical illness polyneuropathy and myopathy. Crit Care 2008;12:238

6 Marx G, Zimmer A, Rothaug J, et al. Chronic pain after surviving sepsis. Crit Care 2006;10:P421

7 Davydow DS, Gifford JM, Desai SV, et al. Depression in general intensive care unit survivors: a systematic review. Intensive Care Med 2009;35:796-809.

8 Parker AM, Sricharoenchai T, Raparla S, et al. Posttraumatic stress disorder in critical illness survivors: a metaanalysis. Crit Care Med 2015:43:1121-9.

9 Cuthbertson BH, Roughton S, Jenkinson D. Quality of life in the five years after intensive care: a cohort study. Crit Care 2010;14:R6.

10 Oeyen SG, Vandijck DM, Benoit DD, et al. Quality of life after intensive care: a systematic review of the literature. Crit Care Med 2010;38:2386-400.

11 Douglas SL, Daly BJ, Kelley CG, et al. Chronically critically ill patients: health-related quality of life and resource use after a disease management intervention. Am J Crit Care 2007;16:447-57.

12 National Institute for Health and Clinical Excellence. Rehabilitation after critical illness in adults. in: NICE clinical guideline 83. London, 2009. Available: https://www.nice.org.uk/guidance/cg83 [Accessed 20 Aug 2019].

13 Brunkhorst F, Weigand M, Pletz M. Revision of the S3-guideline of the German sepsis Society (DSG) and the German interdisciplinary association for intensive and emergency medicine (DIVI): prevention, diagnosis, therapy and aftercare of sepsis, 2018. Available: https://www. awmf.org/leitlinien/detail/l/079-001.html [Accessed 20 Aug 2019].

14 Jensen JF, Thomsen T, Overgaard D, et al. Impact of follow-up consultations for ICU survivors on post-ICU syndrome: a systematic review and meta-analysis. Intensive Care Med 2015;41:763-75.

15 Pattison NA, Dolan S, Townsend P, et al. After critical care: a study to explore patients' experiences of a follow-up service. J Clin Nurs 2007;16:2122-31.

16 Prinjha S, Field K, Rowan K. What patients think about ICU follow-up services: a qualitative study. Crit Care 2009;13:R46.

17 Vijayaraghavan BKT, Willaert X, Cuthbertson BH. Should ICU clinicians follow patients after ICU discharge? no. Intensive Care Med 2018;44:1542-4.

18 Williams TA, Leslie GD. Beyond the walls: a review of ICU clinics and their impact on patient outcomes after leaving hospital. Aust Crit Care 2008;21:6-17.

19 Flaatten H. Follow-up after intensive care: another role for the intensivist? Acta Anaesthesiol Scand 2005;49:919-21.

20 Kvåle R, Ulvik A, Flaatten H. Follow-up after intensive care: a single center study. Intensive Care Med 2003;29:2149-56.

21 Meyer J, Brett SJ, Waldmann C. Should ICU clinicians follow patients after ICU discharge? Yes. Intensive Care Med 2018;44:1539-41.

22 Kahn JM, Angus DC. Health policy and future planning for survivors of critical illness. Curr Opin Crit Care 2007;13:514-8.

23 Starfield B, Shi L, Macinko J. Contribution of primary care to health systems and health. Milbank Q 2005;83:457-502.

24 Hung W. Receipt of primary care linked to high-value care, better health care experience. J Clin Outcome Manage 2019;26:152-5.

25 van Beusekom I, Bakhshi-Raiez F, de Keizer NF, et al. Dutch ICU survivors have more consultations with general practitioners before and after ICU admission compared to a matched control group from the general population. PLoS One 2019;14:e0217225.

26 Gesundheitsberichterstattung des Bundes. Intensivmedizinische Versorgung in Krankenhäusern, 2017. Available: http://www.gbebund.de/oowa921-install/servlet/oowa/aw92/dboowasys921. xwdevkit/xwd_init?gbe.isgbetol/xs_start_neu/\&p_aid=3\&p_aid = $8601121 \&$ nummer $=841 \& p \_s p r a c h e=D \& p \_i n d s p=-\& p \_a i d=72745609$ [Accessed Aug 2019].

27 Thornton J. Covid-19: the challenge of patient rehabilitation after intensive care. BMJ 2020;369:m1787.

28 McGovern M, McGovern C, Parker R. Survivors of critical illness: victims of our success? Br J Gen Pract 2011;61:714-5.

29 Bench S, Cornish J, Xyrichis A. Intensive care discharge summaries for general practice staff: a focus group study. Br J Gen Pract 2016;66:e904-12.

30 O'Brien MA, Rogers S, Jamtvedt G, et al. Educational outreach visits: effects on professional practice and health care outcomes. Cochrane Database Syst Rev 2007:CD000409.

31 Bethea J, Qureshi N, Drury N, et al. The impact of genetic outreach education and support to primary care on practitioner's confidence and competence in dealing with familial cancers. Community Genet 2008;11:289-94

32 Collier A, Rowett D, Allcroft P, et al. Academic detailing of general practitioners by a respiratory physician for diagnosis and management of refractory breathlessness: a randomised pilot study. BMC Health Serv Res 2015;15:193.

33 Schmidt K, Thiel P, Mueller F, et al. Sepsis survivors monitoring and coordination in outpatient health care (SMOOTH): study protocol for a randomized controlled trial. Trials 2014;15:283.

34 Schmidt K, Worrack S, Von Korff M, et al. Effect of a primary care management intervention on mental health-related quality of life among survivors of sepsis: a randomized clinical trial. JAMA 2016;315:2703-11.

35 Prescott HC, Angus DC. Enhancing recovery from sepsis: a review. JAMA 2018;319:62-75.

36 Wagner EH, Austin BT, Von Korff M. Organizing care for patients with chronic illness. Milbank Q 1996;74:511-44.

37 Alexandersen I, Stjern B, Eide R, et al. 'Never in my mind to give up!' A qualitative study of long-term intensive care patients' inner strength and willpower-Promoting and challenging aspects. J Clin Nurs 2019;28:3991-4003.

38 Czerwonka Al, Herridge MS, Chan L, et al. Changing support needs of survivors of complex critical illness and their family caregivers across the care continuum: a qualitative pilot study of towards RECOVER. J Crit Care 2015;30:242-9.

39 Hashem MD, Nallagangula A, Nalamalapu S, et al. Patient outcomes after critical illness: a systematic review of qualitative studies following hospital discharge. Crit Care 2016;20:345

40 Scheunemann LP, White JS, Prinjha S, et al. Post-Intensive care unit care. A qualitative analysis of patient priorities and implications for redesign. Ann Am Thorac Soc 2020;17:221-8.

41 Corner EJ, Murray EJ, Brett SJ. Qualitative, grounded theory exploration of patients' experience of early mobilisation, rehabilitation and recovery after critical illness. BMJ Open 2019;9:e026348.

42 Gehrke-Beck S, Bänfer M, Schilling N. The specific needs of patients following sepsis: a nested qualitative interview study. BJGP Open 2017;1:bjgpopen17X100725.

43 King J, O'Neill B, Ramsay P. Identifying patients' support needs following critical illness: a scoping review of the qualitative literature. Crit Care 2019;23:187.

44 McEvoy P, Richards D. A critical realist rationale for using a combination of quantitative and qualitative methods. $J$ Res Nurs 2006;11:66-78.

45 Sturgiss EA, Clark AM. Using critical realism in primary care research: an overview of methods. Fam Pract 2020;37:143-5.

46 Braun V, Clarke V. Using thematic analysis in psychology. Qual Res Psychol 2006;3:77-101.

47 Lehmkuhl L, Egerod I, Overgaard D, et al. Stimulated by insight: exploration of critical care nurses' experience of research participation in a recovery programme for intensive care survivors. $J$ Clin Nurs 2020;29:1312-22.

48 Girbes ARJ, Beishuizen A. Interfacing the ICU with the general practitioner. Crit Care 2010;14:172-72.

49 Etesse B, Jaber S, Mura T, et al. How the relationships between general practitioners and intensivists can be improved: the general practitioners' point of view. Crit Care 2010;14:R112.

50 Williams TA, Leslie GD, Brearley L, et al. Healthcare utilisation among patients discharged from hospital after intensive care. Anaesth Intensive Care 2010;38:732-9.

51 Fabry GB. Medizindidaktik ein Handbuch für die praxis. 1st edn, 2008.

52 Heintze C, Matysiak-Klose D, Braun V. [Perception of continuous medical education by primary care physicians]. Z Arztl Fortbild Qualitatssich 2005:99:437-42.

53 Anthierens S, Verhoeven V, Schmitz O, et al. Academic detailers' and general practitioners' views and experiences of their academic detailing visits to improve the quality of analgesic use: process evaluation alongside a pragmatic cluster randomized controlled trial. BMC Health Serv Res 2017;17:841.

54 Schwarz CM, Hoffmann M, Schwarz P, et al. A systematic literature review and narrative synthesis on the risks of medical discharge letters for patients' safety. BMC Health Serv Res 2019;19:158.

55 Medlock S, Eslami S, Askari M, et al. Improved communication in post-ICU care by improving writing of ICU discharge letters: a longitudinal before-after study. BMJ Qual Saf 2011;20:967-73.

56 O'Brien BC, Harris IB, Beckman TJ, et al. Standards for reporting qualitative research: a synthesis of recommendations. Acad Med 2014;89:1245-51. 